\title{
Photoelectrochemical Conditioning of MOVPE p-InP Films for Light-Induced Hydrogen Evolution: Chemical, Electronic and Optical Properties
}

\author{
A. G. Muñoz, ${ }^{\mathrm{a}, \mathrm{d}, \mathrm{z}}$ C. Heine, ${ }^{\mathrm{a}}$ M. Lublow, ${ }^{\mathrm{a}}$ H. W. Klemm, ${ }^{\mathrm{a}}$ N. Szabó, ${ }^{\mathrm{b}}$ T. Hannappel, ${ }^{\mathrm{b}}$ \\ and H.-J. Lewerenz ${ }^{\text {a,c }}$ \\ ${ }^{a}$ Institute for Solar Fuels and Energy Storage Materials and ${ }^{b}$ Institute for Materials for Photovoltaics, \\ Helmholtz-Centre Berlin for Materials and Energy, 14109 Berlin, Germany \\ ${ }^{c}$ Joint Center for Artificial Photosynthesis, California Institute of Technology, Pasadena, California 91125, USA
}

\begin{abstract}
Homoepitaxial p-InP(100) thin films prepared by MOVPE (metallorganic vapor phase epitaxy) were transformed into an InP/oxidephosphate/Rh heterostructure by photoelectrochemical conditioning. Surface sensitive synchrotron radiation photoelectron spectroscopy indicates the formation of a mixed oxide constituted by $\operatorname{In}\left(\mathrm{PO}_{3}\right)_{3}, \mathrm{InPO}_{4}$ and $\mathrm{In}_{2} \mathrm{O}_{3}$ as nominal components during photo-electrochemical activation. The operation of these films as hydrogen evolving photocathode proved a light-to-chemical energy conversion efficiency of $14.5 \%$. Surface activation arises from a shift of the semiconductor electron affinity by $0.44 \mathrm{eV}$ by formation of $\mathrm{In}-\mathrm{Cl}$ interfacial dipoles with a density of about $10^{12} \mathrm{~cm}^{-2}$. Predominant local $\mathrm{In}_{2} \mathrm{O}_{3}$-like structures in the oxide introduce resonance states near the semiconductor conduction band edge imparting electron conductivity to the phosphate matrix. Surface reflectance investigations indicate an enhanced light-coupling in the layered architecture.
\end{abstract}

(C) 2013 The Electrochemical Society. [DOI: 10.1149/2.016304jss] All rights reserved.

Manuscript submitted January 3, 2013; revised manuscript received January 22, 2013. Published February 8, 2013.

Solar hydrogen generation from water represents a viable route for establishing a carbon-neutral energy infrastructure based on renewable energy resources. ${ }^{1-4}$ To achieve this long-term objective, numerous approaches are currently being pursued comprising adapting systems derived from photosynthesis, ${ }^{5-7}$ identification of appropriate catalysts, ${ }^{8}$ development of transition metal oxide photoelectrodes ${ }^{9,10,11}$ as well as devising efficient semiconductor tandem structures. ${ }^{12-14}$ Because biomimetic systems inspired by natural photosynthesis are characterized by rather low theoretical efficiencies, ${ }^{6}$ the use of photoresponsive semiconductor materials for the splitting of water appears currently most promising. It can be shown that dual-bandgap systems reach theoretically efficiencies well above $40 \%$ at AM1.5. ${ }^{15}$ The development horizon suggests therefore the use of technologically advanced semiconductor materials which would allow comparably fast technical realization. Further, the orthogonalization of charge carrier and photon pathways as well as an increased built-in potential by interfacial doping was recently exploited to achieve efficiencies near $10 \%$ using $\mathrm{Si}$ as substrate. ${ }^{16}$

p-type InP is one of the most efficient photocathode materials for hydrogen evolution available. Heller and Vadimsky ${ }^{17}$ have shown three decades ago that hydrogen evolution can occur with an efficiency of $12 \%$ if rhodium is deposited as catalytically active and optically transparent thin-film on top of an $\mathrm{In}_{2} \mathrm{O}_{3} / \mathrm{InP}$ structure. In this work, a new approach based on thin film photoelectrodes is presented. The photocathode is realized by homoepitaxial growth of thin films onto InP wafers which allows the use of liftoff procedures already known for photovoltaic systems. ${ }^{18,19}$ The removal of the thin film photocathodes from the growth substrate is thereby possible after fabrication of the devices. This approach reduces production costs, which is a decisive factor for many III-V devices. In this report, we evaluate the applicability of homoepitaxial devices with emphasis in the interfacial chemical and electronic properties of the $\mathrm{Rh} /$ phosphate-oxide/InP composites. Furthermore, with decreasing material thickness, light incoupling techniques, extensively discussed for solar cells, ${ }^{20,21}$ become increasingly significant for the photoelectrochemical thin film device.

\section{Experimental}

Preparation of homoepitaxial thin-film InP photoelectrodes.- 3 $\mu \mathrm{m}$ thick homoepitaxial, Zn-doped p-InP films with (100)-orientation and doping density $N_{\mathrm{p}}=3 \times 10^{17} \mathrm{~cm}^{-3}$ were deposited by Met-

\footnotetext{
${ }^{\mathrm{d} P r e s e n t}$ address: GRSmbH, Global Research for Safety, 38122 Braunschweig, Germany.

${ }^{\mathrm{z} E-m a i l: ~ a n d r e s . m u n o z @ g r s . d e ~}$
}

allorganic Vapor Phase Epitaxy (MOVPE). As growth substrates, $350 \mu \mathrm{m}$ thick (100)-oriented InP wafers $\left(N_{\mathrm{p}}=10^{18} \mathrm{~cm}^{-3}\right)$ were used. Trimethyl indium (TMI) and tertiary butylphosphine (TBP) served as precursors. Doping of the epitaxial films was realized by addition of diethyl zinc. After growth at $\mathrm{T}=875 \mathrm{~K}$, the samples were cooled down to $775 \mathrm{~K}$ in the presence of TBP to prevent thermal decomposition. Below $775 \mathrm{~K}$, the TBP stabilization was turned off which led to $\mathrm{P}$ depletion and an In-rich $(2 \times 4)$ reconstructed surface. ${ }^{22-24}$ $\mathrm{P}$-atoms form a mixed dimer with In-atoms along the $[-110]$ direction that terminate the surface while In-bonds extend in [110] direction and complete the $(2 \times 4)$ reconstruction (see Figure 1a).

(Photo)electrochemistry was carried out in a three-electrode arrangement with a Pt counter electrode for surface conditioning; a carbon electrode was used for efficiency tests. A saturated calomel (SCE) electrode was used as reference and all potentials are referred to SCE. All solutions were deaerated by $\mathrm{N}_{2}$ purging. The protocol a)

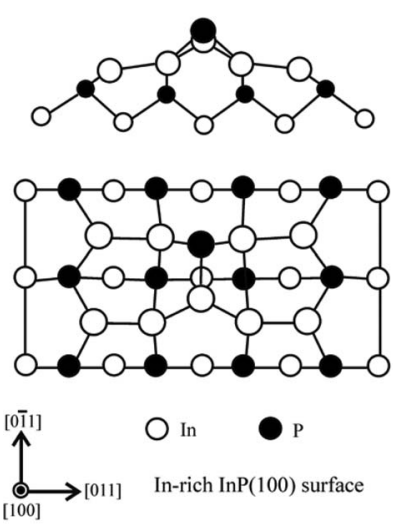

b) Potential / V vs SCE

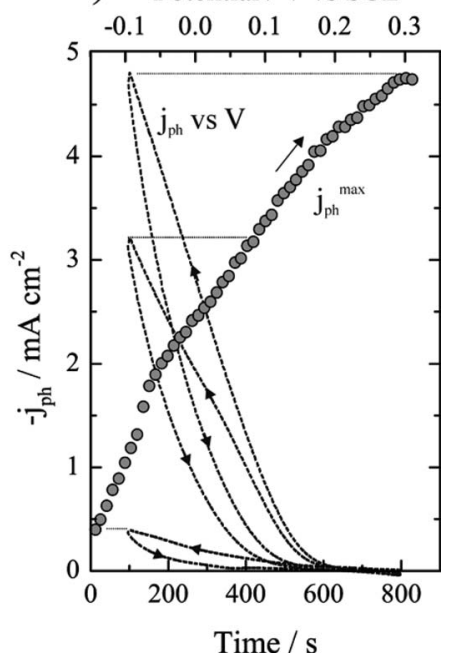

Figure 1. (a) Side and top view of the atomic surface structure of a reconstructed InP(100): $2 \times 4$ surface; (b) Photoelectochemical conditioning of the homoepitaxial $\operatorname{InP}(100): 2 \times 4$ thin-film by repeated cycles in $1 \mathrm{M} \mathrm{HCl}$ (dotted curves). Increased photocurrent densities are observed with increasing cycle numbers. Circles indicate the photocurrent density enhancement at $-0.1 \mathrm{~V}$. Scan rate $50 \mathrm{mVcm}^{-1}$, light intensity $100 \mathrm{mWcm}^{-2}$. 


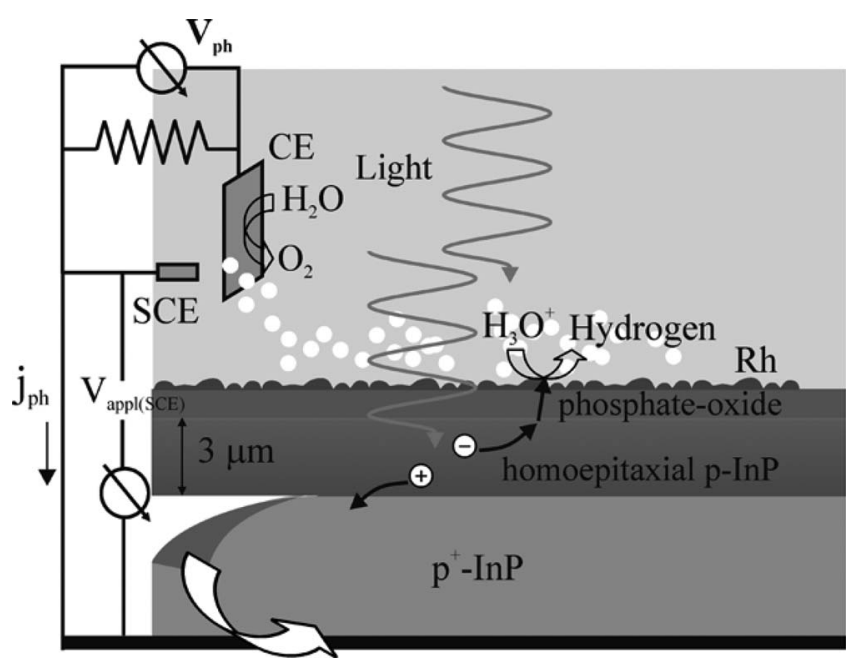

Figure 2. Schematic of the $\mathrm{p}-\mathrm{InP} / \mathrm{phosphate}-\mathrm{oxide} / \mathrm{Rh}$ light converting device in a three-electrode setup of the electrochemical cell with Pt counter electrode (CE) and saturated calomel reference electrode (SCE).

for the transformation of the initial $\operatorname{InP}(100): 2 \times 4$ surface by photoelectrochemical conditioning into a device structure consists of three steps: initially, the fresh MOVPE deposited layer was etched $5 \mathrm{~s}$ in a solution of $0.5 \%$ of $\mathrm{Br}_{2}$ in methanol. Subsequently, surface conditioning was realized by potentiodynamic cycling under illumination between -0.1 and $0.3 \mathrm{~V}$ in a $1 \mathrm{M} \mathrm{HCl}$ solution. The photocurrent increases with cycling times (dashed curves in Fig. 1b). This indicates an enhancement of the electrocatalytic activity for the photo-induced hydrogen evolution. Finally, a thin Rh-layer was photoelectrochemically deposited from a solution of $5 \mathrm{mM} \mathrm{RhCl}_{3}+0.5 \mathrm{M} \mathrm{NaCl}+$ 5 vol. $\%$ isopropanol at constant potential: $V_{\text {dep }}=-0.2 \mathrm{~V}$. A deposition charge of $33.7 \mathrm{mC} \mathrm{cm}^{-2}$ was measured. The deposition current follows the Cottrell behavior, i.e. the reduction of the metal ions is diffusion-controlled. The photocathodes were finally tested in $1 \mathrm{M}$ $\mathrm{HClO}_{4}$ upon illumination with a W-I white-light source.

Structural, optical and electronic characterization.- Tapping Mode Atomic Force Microscopy (TM-AFM) was used for the characterization of the surface morphology. The electronic properties and chemical composition of the homoepitaxial thin InP-film was investigated after each treatment step by surface sensitive Synchrotron Radiation Photoelectron Spectroscopy (SRPES). Electrochemical experiments were performed in-system in a specially designed threeelectrode cell attached to the analysis system at the U49/2 beam line at BESSY II (Berlin, Germany). ${ }^{25}$ During electrochemical conditioning the cell was held in a protective $\mathrm{N}_{2}$ atmosphere to avoid contamination of the samples by ambient air. Measurements of the reflectance behavior of bulk InP (as reference) and the Rh/oxide-phosphate/InP device were carried out by a Perkin Elmer UV-VIS spectrometer at near-normal incidence.

\section{Results and Discussion}

Efficiency assessment.- The current-voltage characteristic of the conditioned thin film photoelectrode was determined in $1 \mathrm{M} \mathrm{HClO}_{4}$ under illumination (W-I lamp). The operation principle of the photoelectrochemical cell is illustrated in Fig. 2, indicating the device architecture, light-induced electron-hole pair generation and the respective evolution of hydrogen at the working electrode and water oxidation at the counter electrode. The measured photocurrent density is shown in Fig. 3. One of the ways to define the efficiency of the photocathode upon hydrogen evolution is given by:

$$
\varepsilon=-\left[j_{\mathrm{mpp}}\left(V_{\mathrm{mpp}}-V_{\mathrm{her}}^{0}\left(j_{\mathrm{mpp}}\right)\right)\right] / P_{i}
$$

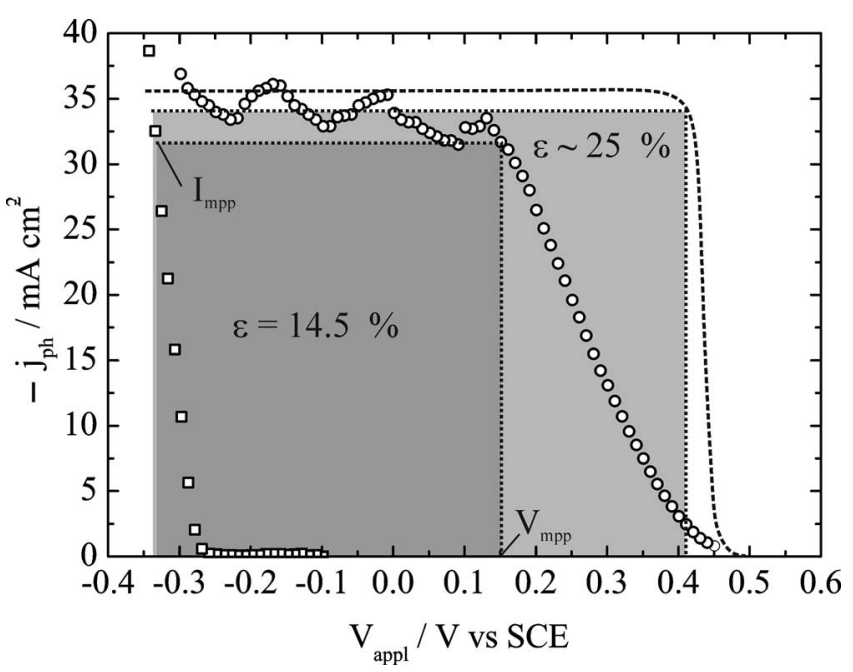

Figure 3. (०) Photocurrent-voltage behavior of the $\mathrm{p}-\mathrm{InP} / \mathrm{phosphate}-\mathrm{oxide} / \mathrm{Rh}$ photoelectrode in $1 \mathrm{M} \mathrm{HClO}_{4}$. Light intensity: $105 \mathrm{mWcm}^{-2}$ (W-I lamp); $(\square)$ the dark current behavior of metallic (bulk) $\mathrm{Rh}$ in $1 \mathrm{M} \mathrm{HClO}_{4} ; \mathrm{V}_{\mathrm{mpp}}$, $\mathrm{j}_{\mathrm{mpp}}$ denote voltage and current at the maximum power point; dotted curve: theoretical I-V characteristic with optimized charge transfer.

Here, $j_{\mathrm{mpp}}$ and $V_{\mathrm{mpp}}$ refer to the current density and potential, respectively, at the maximum power point, while $P_{\mathrm{i}}$ is the power of the incident light. $V_{\text {her }}^{0}\left(\mathrm{j}_{\mathrm{mpp}}\right)$, in turn, is the corresponding potential for which the hydrogen evolution reaction (her) occurs with identical current density $\mathrm{j}_{\mathrm{mpp}}$ at the Rh-wire. According to Fig. 3, a maximum light-to-hydrogen conversion efficiency of $14.5 \%$ is obtained. Despite the improved efficiency in comparison to earlier reports, ${ }^{17}$ the slope of the current curve behind the onset appears still somewhat sluggish and affects the quality of the fill factor. Perturbations of the current signal for saturated photocurrents result from the kinetics of hydrogen gas bubble formation at the surface and subsequent release into the solution. The maximum photovoltage reaches $0.72 \mathrm{~V}$, which is smaller than the maximal achievable contact potential difference between $\mathrm{p}$ $\mathrm{InP}$ and the hydrogen redox couple of about $0.9 \mathrm{~V}:\left(\Phi_{\mathrm{her}}-E_{\mathrm{F}(\mathrm{InP})}\right)$ with $\Phi_{\text {her }}$ as the work function of the her, set at $4.6 \mathrm{eV}$. These facts point to further possible improvements as indicated by the dashed curve in Fig. $2 b$ which suggests a theoretical maximum efficiency of $>20 \%$ after further improvement of the fill factor by enhanced electron transfer across the interfacial region. Further details will be discussed below.

The electrode stability was tested at least for half an hour of operation at $0 \mathrm{~V}_{\mathrm{SCE}}$. The mean current showed a slight increase during this time. The same electrode showed no losses of its activity after storing the electrode in a desiccator for several days. As shown in the following section, HR-TEM pictures performed after the passage of a cathodic charge of $34.8 \mathrm{~cm}^{-2}$ did not show any evidence of electrode corrosion.

Structural, chemical and electronic properties. - Fig. 4a shows a high resolution transmission electron microscopy (HR-TEM) picture of a cross sectional cut of deposited photoelectrodes after the passage of a cathodic charge of $34.8 \mathrm{Ccm}^{-2}$. It can be seen that the $\mathrm{InP} /$ phosphate-oxide interface remains unaltered for extended operation times. This is because of (i) the complete surface coverage by the $\mathrm{Rh}$ film and (ii) the conduction band states in the oxide film below the conduction band edge of InP (this provides an electron drain avoiding their interfacial accumulation and photodecomposition: see discussion below). The metal film consists of a conglomerate of nanoparticles with 10-30 nm of diameter (Fig. 4a). Different lattice plane orientations within the grains reveal their polycrystalline nature. No structure, however, is observed at the phosphate-oxide film, the thickness of which is about 5-7 nm. This exceeds, in principle, the tunneling distance. ${ }^{26}$ Consequently, a charge transport mechanism different from direct electron tunneling has to be inferred. 


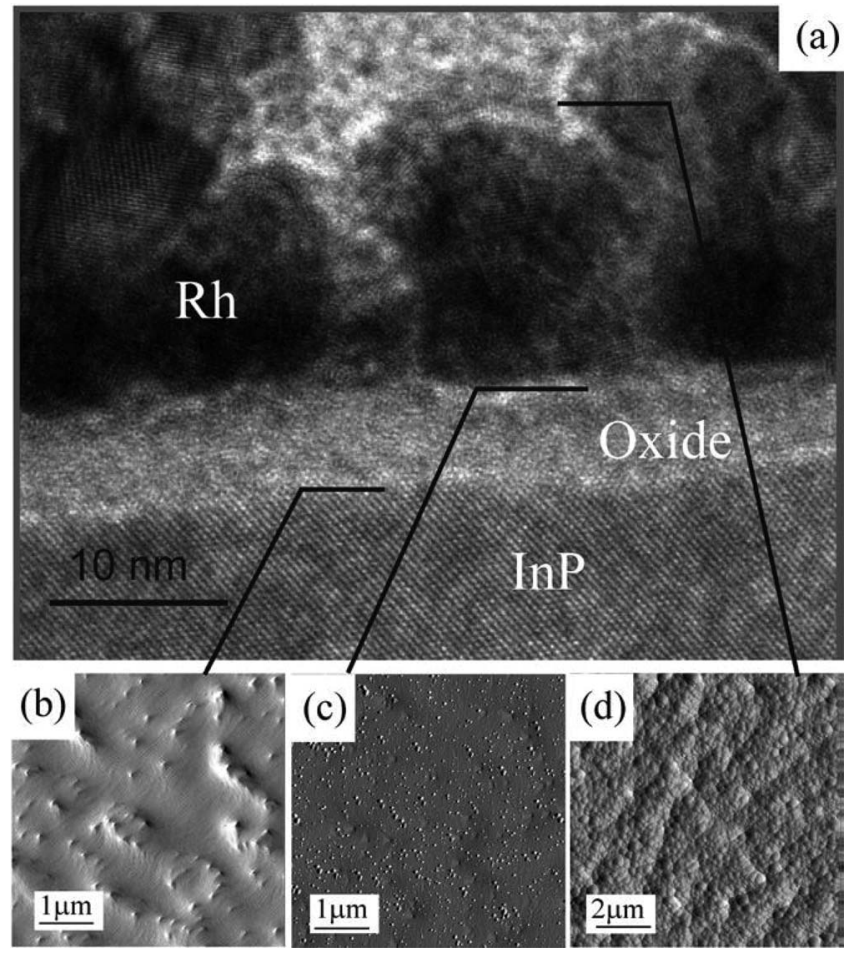

Figure 4. Side and top view microscopy analysis of the prepared structure after cathodic charge has been passed; (a) TEM cross sectional analysis of the fully prepared device, showing the Rh nanoparticles with crystalline cores, an amorphous interfacial film and the crystalline InP homoepitaxial thin-film; (b) TM-AFM image (amplitude mode) illustrating the initial InP surface; (c) TM-AFM image of the oxidized surface and (d) after the compact $\mathrm{Rh}$ layer was deposited. (a) and (d) were taken after the passage of a cathodic charge of $34.8 \mathrm{Ccm}^{-2}$ flowed at $0 \mathrm{~V}_{\mathrm{SCE}}$.

The lateral surface/interface morphologies were imaged by TMAFM after each stage of device preparation. Fig. 4b, 4c and 4d, shows the surface of the homoepitaxial InP thin film as cleaned and etched in bromide solution (b), after formation of the oxide film (c) and after Rh electrodeposition (d). Image (d) indicates a closed metal film

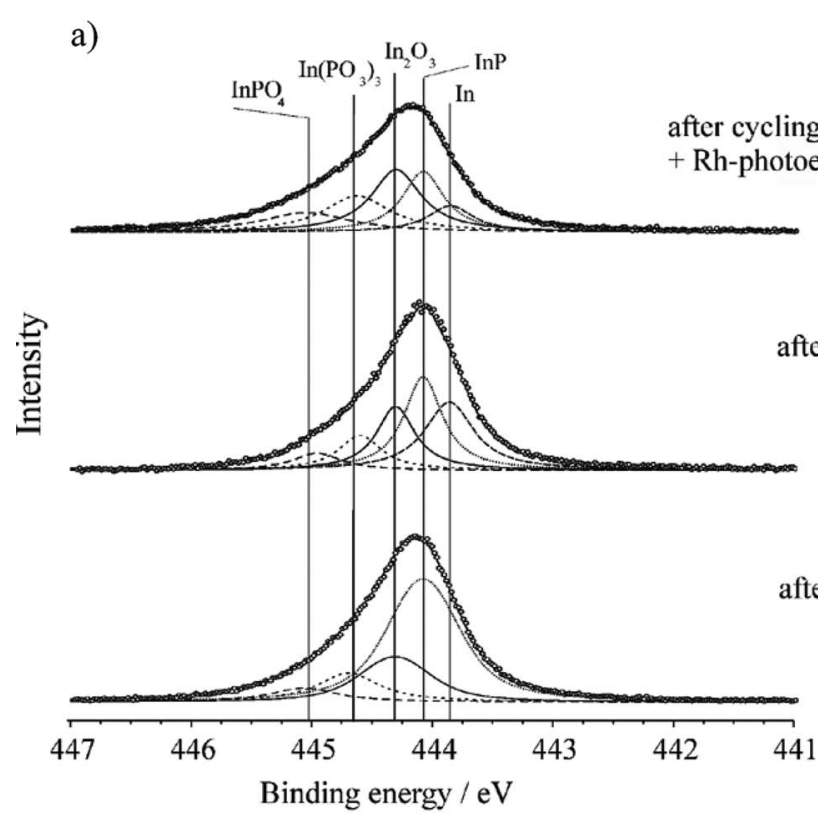

in agreement with electron transmission studies. Picture (c) shows the formation of precipitates of $10-100 \mathrm{~nm}$ after oxide film formation, which are attributed to metallic In by regarding spectroscopic investigations.

The surface oxidation by photoelectrochemical cycling between $-0.1 \mathrm{~V}$ and $0.3 \mathrm{~V}_{\mathrm{SCE}}$ in $\mathrm{HCl}$ increases the activity for hydrogen evolution (see Fig. 1b). This treatment causes surface photodecomposition with formation of In-islands according to:

$$
\mathrm{InP}+3 \mathrm{e}_{\mathrm{CB}}^{-}(\mathrm{h} \nu)+3 \mathrm{H}^{+} \rightarrow \mathrm{In}+\mathrm{PH}_{3(\mathrm{~g})}
$$

$\left(V^{0}=-0.6 \mathrm{~V}_{\mathrm{SCE}}\right)$. Formed indium can further oxidize by holeinjection according to:

$$
2 \mathrm{In}+3 \mathrm{H}_{2} \mathrm{O}+6 \mathrm{~h}^{+} \rightarrow \mathrm{In}_{2} \mathrm{O}_{3}+6 \mathrm{H}^{+}
$$

at $\mathrm{V}>V^{0}=-0.412 \mathrm{~V}_{\mathrm{SCE}}$. Moreover, the formation of indium phosphates is possible according to:

$$
\begin{gathered}
3 \mathrm{InP}+15 \mathrm{H}_{2} \mathrm{O}+24 \mathrm{~h}^{+} \rightarrow \mathrm{In}\left(\mathrm{PO}_{3}\right)_{3}+2 \mathrm{In}(\mathrm{OH})_{3}+24 \mathrm{H}^{+} \text {and } \\
\mathrm{InP}+4 \mathrm{H}_{2} \mathrm{O}+8 \mathrm{~h}^{+} \rightarrow \mathrm{InPO}_{4}+8 \mathrm{H}^{+} .
\end{gathered}
$$

The standard potentials for reactions 4 and 5 are $-0.92 \mathrm{~V}_{\mathrm{SCE}}$ and $-0.84 \mathrm{~V}_{\mathrm{SCE}}$, respectively. Finally, the formation of surface $\mathrm{InCl}$ is expected at $V^{0}=-0.38 \mathrm{~V}_{\mathrm{SCE}}$ :

$$
\mathrm{In}+\mathrm{Cl}^{-}+\mathrm{h}^{+} \rightarrow \mathrm{InCl} \text {. }
$$

The reaction schemes for the cathodic and anodic decomposition routes reflect the complex interfacial chemical composition arising from cycling in $\mathrm{HCl}$. The deconvolution of the In $3 \mathrm{~d}_{5 / 2}$ and $\mathrm{P} 2 \mathrm{p}$ core level SRPES spectra obtained after electrochemical cycling and photo-electrodeposition of Rh (depicted in Fig. 5) indicates that the ultrathin interfacial film consists of a complex oxide which can be described as a ternary oxide $\operatorname{In}_{x} \mathrm{P}_{\mathrm{y}} \mathrm{O}_{\mathrm{z}}$ with localized environments where structures resembling those of $\mathrm{In}\left(\mathrm{PO}_{3}\right)_{3}, \mathrm{InPO}_{4}$ and $\mathrm{In}_{2} \mathrm{O}_{3}$ predominate. The core level $\mathrm{P} 2 \mathrm{p}$ signal obtained after each conditioning step can be in principle deconvoluted in three components at $128.4 \mathrm{eV}$, $132.45 \mathrm{eV}$ and $133.2 \mathrm{eV}$ which can be assigned to $\mathrm{InP}, \operatorname{In}\left(\mathrm{PO}_{3}\right)_{3}$ and $\mathrm{InPO}_{4}$ respectively (Fig. 5). The spectrum taken after the treatment in the $\mathrm{Br}_{2}$-methanol solution clearly indicates that the formation of an oxide containing phosphates starts already during this first step.

b)

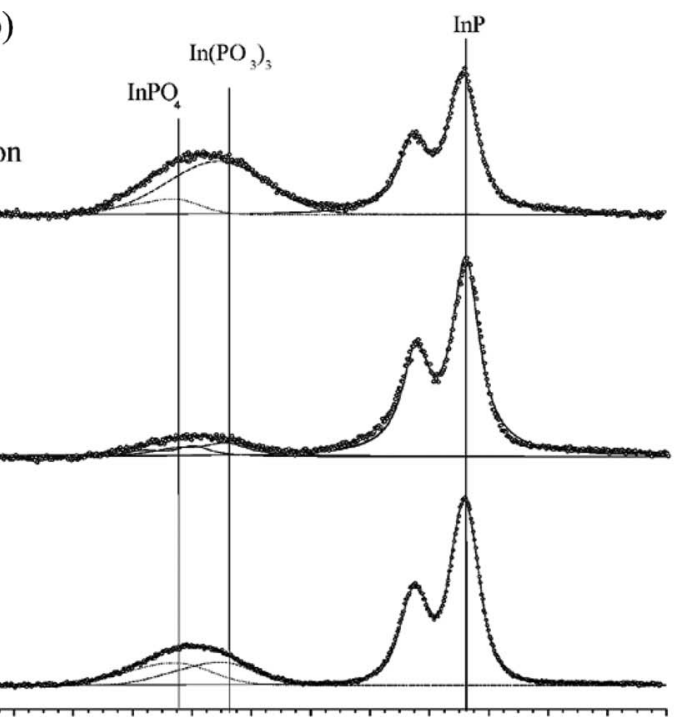

$\begin{array}{lllllllllllll}137 & 136 & 135 & 134 & 133 & 132 & 131 & 130 & 129 & 128 & 127 & 126 & 125\end{array}$

Binding energy / eV

Figure 5. SRPES In $3 d_{5 / 2}$ (a) and $P 2 p$ (b) core level spectra of homoepitaxial InP (100) layers taken after each conditioning. Chemical compounds associated with the observed chemical shifts of the respective binding energies are indicated in the figures. The spectra were recorded at excitation energies of $600 \mathrm{eV}$ (a) and $200 \mathrm{eV}$ (b) respectively. 

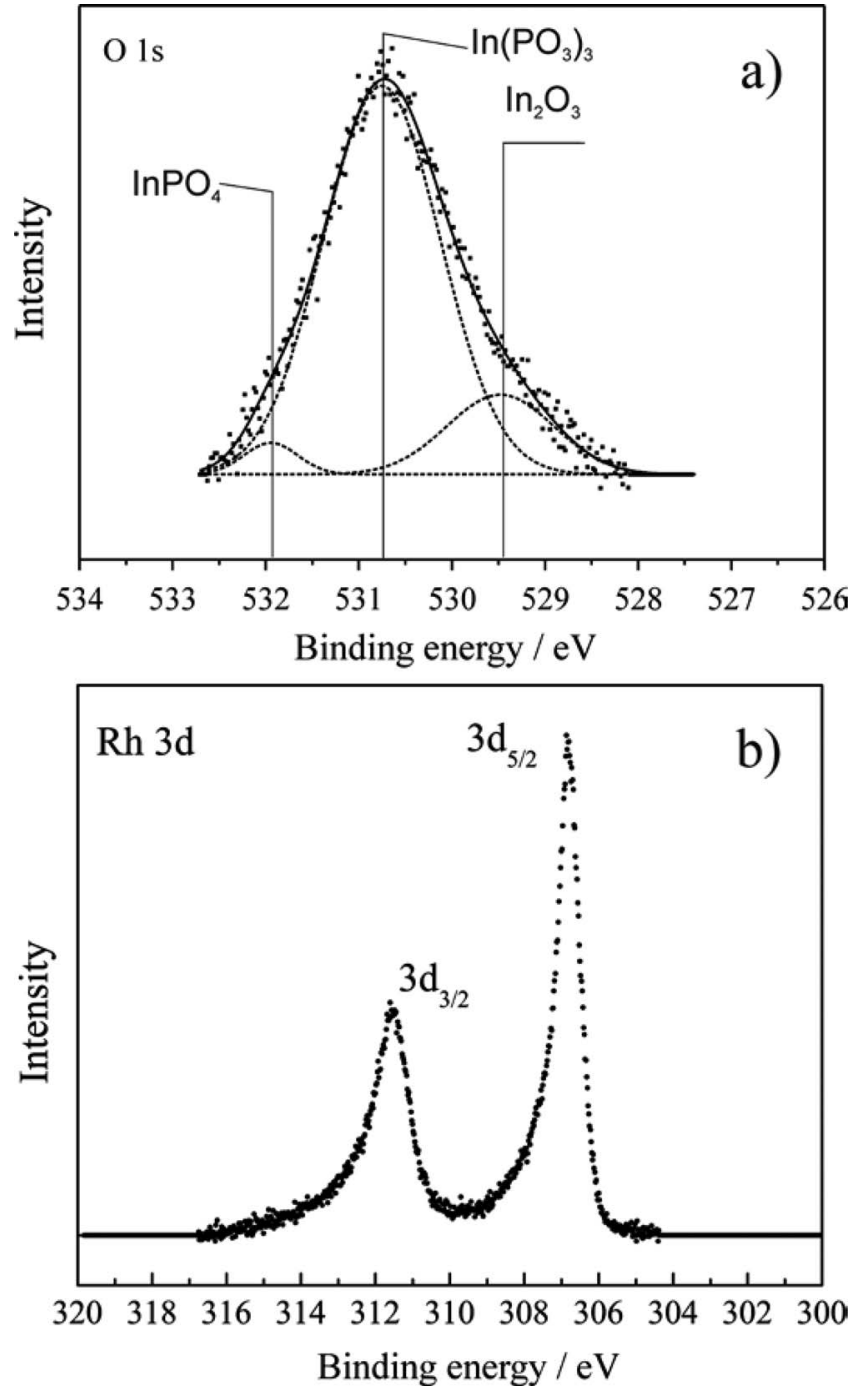

Figure 6. SRPES of (a) O 1s and (b) Rh $3 \mathrm{~d}$ core level spectra of homoepitaxial InP (100) layers taken after photoelectrochemical conditioning. Excitation energy: $580 \mathrm{eV}$ (a) and $600 \mathrm{eV}$ (b).

The identification of $\operatorname{In}\left(\mathrm{PO}_{3}\right)_{3}$ and $\mathrm{InPO}_{4}$ is supported by the appearance of a line at $444.75 \mathrm{eV}$ and $445.05 \mathrm{eV}$ in the In $3 \mathrm{~d}_{5 / 2}$ signal, ${ }^{27,28}$ respectively, after deconvolution as shown in Fig. 5 for each of the three conditioning steps. The spectra also show the presence of a component at $444.3 \mathrm{eV}$, which can be assigned to $\mathrm{In}_{2} \mathrm{O}_{3}$. The increase of the signal of $\operatorname{In}_{2} \mathrm{O}_{3}$ in the passive layer relative to the signal of the substrate can in principle be interpreted in terms of an increase of the $\mathrm{In}_{2} \mathrm{O}_{3}$ proportion in the film.

Furthermore, the electrochemical cycling leads to the formation of In metal, as indicated by the appearance of a significant peak at $443.85 \mathrm{eV}$ after the deconvolution of the In $3 \mathrm{~d}_{5 / 2}$ signal. This is a result of the photo-decomposition reaction $2 . \mathrm{In}_{2} \mathrm{O}_{3}$ is the main chemical species in the oxide layer after the photoelectrochemical conditioning. The corresponding intensity ratios, deduced from the In $3 \mathrm{~d}$ spectrum are: $r=I\left(\operatorname{In}_{2} \mathrm{O}_{3}\right) / \mathrm{I}\left(\mathrm{InPO}_{4}\right)=1.83$ and $r=I\left(\operatorname{In}_{2} \mathrm{O}_{3}\right) / \mathrm{I}\left[\left(\operatorname{In}\left(\mathrm{PO}_{3}\right)_{3}\right]\right.$ $=1.30$, where $I_{\mathrm{i}}$ represents the integrated signal intensity. The $\mathrm{O} 1 \mathrm{~s}$ core level line can be deconvoluted in three components at $529.45 \mathrm{eV}$, $530.75 \mathrm{eV}$ and $531.9 \mathrm{eV}$ (see Fig. 6a). The first and latter components can be ascribed to $\mathrm{In}_{2} \mathrm{O}_{3}$ and $\mathrm{InPO}_{4}$ respectively. ${ }^{27}$ There is no ascertained information about the energy position of the line corresponding to $\mathrm{In}\left(\mathrm{PO}_{3}\right)_{3}$. In agreement with $\mathrm{P} 2 \mathrm{p}$ and $\mathrm{In} 3 \mathrm{~d}$ core line spectra, it is reasonable to assign the line at $530.75 \mathrm{eV}$ to this compound. The intensity relation $r=I\left(\mathrm{In}_{2} \mathrm{O}_{3}\right) / \mathrm{I}\left[\left(\mathrm{In}\left(\mathrm{PO}_{3}\right)_{3}\right] \times(9 / 1.5)=1.16\right.$, where the multiplying factor was introduced to account for the atomic relation $\mathrm{In} / \mathrm{O}$, indicates that oxygen atoms are equally balanced in the oxide. The presence of metallic $\mathrm{Rh}$ is indicated, on the other hand, by a sharp line at $306.87 \mathrm{eV}$ assigned to the $3 \mathrm{~d}_{5 / 2}$ line (see Fig. 6b).

The formation of $\mathrm{In}_{2} \mathrm{O}_{3}$ by direct oxidation of $\mathrm{InP}$, as given by reaction 4 , is thermodynamically unfavorable. The dangling bonds of surface In atoms react with water, introducing $\mathrm{O}$ atoms into the In-P bonds to form In-O-P bonds. ${ }^{29}$ This process is energetically more favorable than the formation of In-O-In or P-O-P bonds. ${ }^{30}$

It was reported that the anodization of InP leads to the formation of compositionally inhomogeneous oxides. For instance, P-rich oxides are formed galvanostatically on $\operatorname{InP}(100)$ by applying a current of $15 \mu \mathrm{A} \mathrm{cm}{ }^{-2}$ in aqueous solutions. The inner part of such oxides consists of $\operatorname{In}\left(\mathrm{PO}_{3}\right)_{3}$, whiles $\operatorname{In}_{2} \mathrm{O}_{3}$ predominates in the outermost part of the film. ${ }^{31,32}$ This was explained in terms of a higher migration rate of $\mathrm{In}^{+3}$, which occurs by a hopping mechanism through cationic defects from the InP-oxide- to the oxide-electrolyte interface, aided by the electric field. ${ }^{33}$ The migration of $\mathrm{P}$ atoms, on the other hand, results from an inward movement of $\mathrm{O}^{2-}$ ions by translocation of $\mathrm{P}-\mathrm{O}$ bonds. The outward migration of $\mathrm{In}^{3+}$ by a field assisted mechanism seems however improbable, since the electrochemical conditioning is performed under semiconductor depletion conditions (photoelectrochemical cathodic region). The driving force for transport is given by the large chemical potential differences (represented by the large overpotentials of reactions $2-6$ in the conditioning potential window.

It was observed that the relation between the intensities of the $\mathrm{P}$ $2 p$ lines for $\mathrm{InPO}_{4}$ and $\left.\mathrm{In}\left(\mathrm{PO}_{3}\right)_{3}, r=\mathrm{I}(\mathrm{InPO})_{4}\right) / I\left[\operatorname{In}\left(\mathrm{PO}_{3}\right)_{3}\right]$, increases with the excitation energy as follow: $\mathrm{h} \nu=200 \mathrm{eV}, r=0.62 ; \mathrm{h} \nu=335$ $\mathrm{eV}, r=4.146 ; \mathrm{h} \nu=600 \mathrm{eV}, r=6.75$, after the electrochemical cycling in $\mathrm{HCl}$. This tendency indicates that $\mathrm{In}\left(\mathrm{PO}_{3}\right)_{3}$ forms preferentially at the outer part of the film whereas $\mathrm{InPO}_{4}$ remains close to the InP substrate.

SRPES valence band spectra measured after each treatment step show an energetically unchanged double peak at $17.40 \mathrm{eV}$ and $18.15 \mathrm{eV}$, which can be assigned to the In $4 \mathrm{~d}$ core level signal ${ }^{34}$ (see Fig. 7). The former signal arises from InP. The low binding energy region of the spectra shows characteristic spectral features indicated by arrows, which can be assigned to $\mathrm{O} 2 \mathrm{p}$ emission signals. ${ }^{35,36} \mathrm{Be}-$ tween the Fermi level and $6 \mathrm{eV}$ a broad emission signal from the d-band of Rh is also expected. ${ }^{37}$ These spectra can be compared with valence band spectra reported in Ref. 35 and 28. It should be noted that the appearance of a feature at $3.3 \mathrm{eV}$ is clearly related to $\operatorname{In}_{2} \mathrm{O}_{3}$. Whereas those at $5.2 \mathrm{eV}$ and $9.1 \mathrm{eV}$ can be rather assigned to indium phosphate with low $\mathrm{P}$ content. From these results, it can be inferred, that the electrochemical cycling in $\mathrm{HCl}$ leads to an $\mathrm{In}_{2} \mathrm{O}_{3}$-like surface structure. On regarding the valence band spectra after each treatment step, it can be seen that after photoelectrochemical deposition of Rh, the $\mathrm{P}$ content in the surface oxide increases, leaving an oxide surface similar to that after etching. This fact is in line with the higher relation $\mathrm{I}\left(\mathrm{In}_{2} \mathrm{O}_{3}\right) / \mathrm{I}\left[\left(\mathrm{In}\left(\mathrm{PO}_{3}\right)_{3}\right]\right.$ after first and third conditioning step in comparison with that after cycling (see Fig. 5). The initial rising part close to Fermi level of valence band spectra can be assigned to the signal from the substrate. ${ }^{36}$ The linear extrapolation to zero intensity indicates the energy position of the valence band maximum at the surface by $0.55 \pm 0.05 \mathrm{eV}$. Assuming $\mathrm{E}_{\mathrm{F}}-\mathrm{E}_{\mathrm{CB}}=0.1 \mathrm{eV}$, than a semiconductor band bending of $0.45 \mathrm{eV}$ can be calculated. The semiconductor band bending is related to charge exchange between the semiconductor bands and surface states. Fermi level pinning was reported to occur at the neutrality level estimated $1.0 \mathrm{eV}$ above the $\mathrm{E}_{\mathrm{VBM}} \cdot{ }^{38,39}$ This would imply a band bending of $\sim 0.9 \mathrm{eV}$. In our case, it is feasible, however, that part of the band bending is absorbed by the dielectric oxide film.

The low binding energy part of the spectrum after photoelectrodeposition of $\mathrm{Rh}$ shows a Fermi edge at $\sim-0.30 \mathrm{eV}$. This shift was analyzed by Horn et al., ${ }^{40}$ who attributed this to a photovoltage arising from non-equilibrium effects during photoemission at the metalsemiconductor interface. The shift of the Fermi level toward lower energies causes a retraction of the semiconductor band bending given 

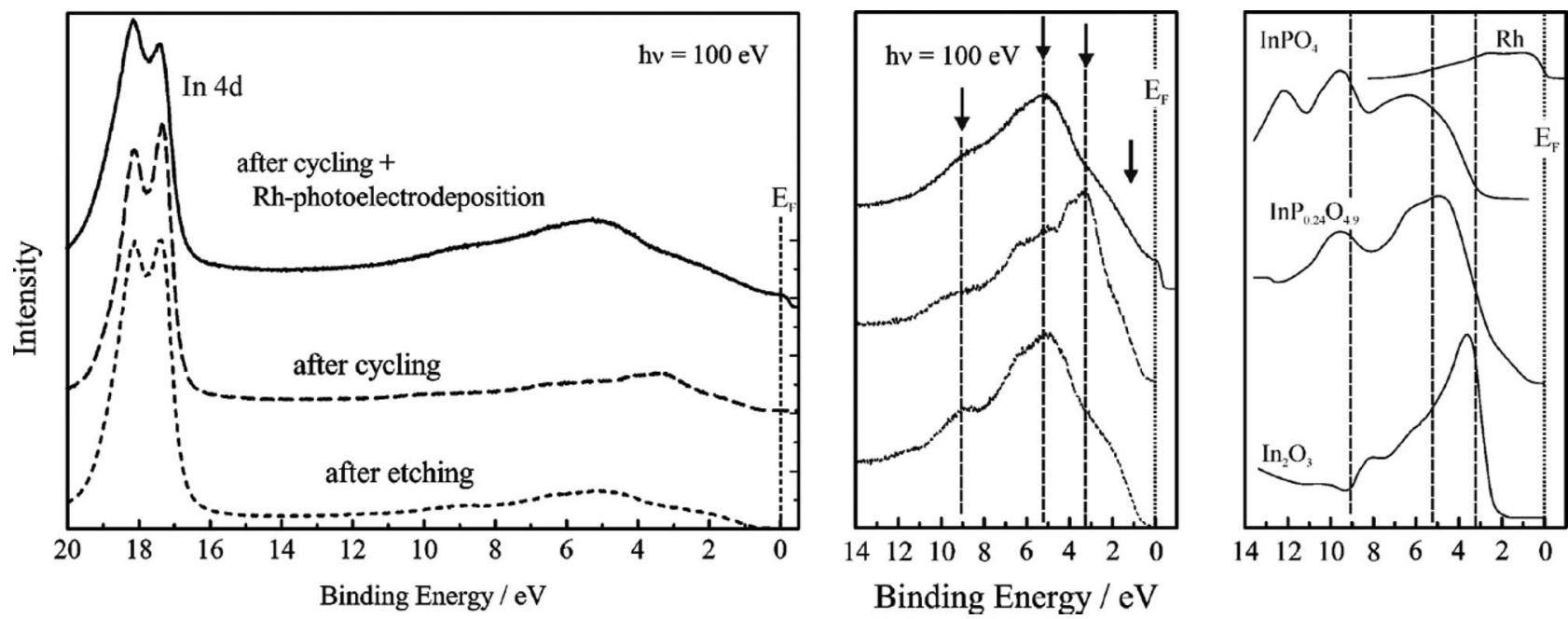

Figure 7. SRPES valence band spectra obtained after each conditioning step at $h \nu=100 \mathrm{eV}$. Right: reference spectra for different In compounds ${ }^{28,35}$ and Rh. ${ }^{37}$

by the measured Fermi level shift. Thus, the equilibrium band bending can be calculated by adding the Fermi shift to the calculated band bending from valence band spectra: so it results $\sim 0.75 \mathrm{eV}$. This value, however, may change depending on the dielectric response of the oxide.

$\mathrm{In}_{2} \mathrm{O}_{3}$ is an n-type semiconductor with a direct bandgap $E_{\mathrm{g}}$ $=3.75 \mathrm{eV}^{41}$ An electron affinity of $4.45 \mathrm{eV}$ was reported in Ref. 40. This value is in line a value of $4.4 \pm 0.1 \mathrm{eV}$ reported by Klein ${ }^{35}$ for the work function of evaporated $\operatorname{In}_{2} \mathrm{O}_{3}$ films. Because of the high doping level of $\operatorname{In}_{2} \mathrm{O}_{3}$, it is feasible that the Fermi level is close to the conduction band edge. ${ }^{42}$ The extrapolation of the leading edge of high energy electrons in UPS spectra (Fig. 8) gives the position of the valence band maximum at the oxide surface, $\mathrm{E}_{\mathrm{VBM}}$. They are $4.19 \mathrm{eV}$, $3.73 \mathrm{eV}$ and $3.06 \mathrm{eV}$ after etching, cycling and photoelectrochemical deposition of $\mathrm{Rh}$, respectively. The secondary electron cutoff, on the other hand, was set at $17.09 \mathrm{eV}, 16.69 \mathrm{eV}$ and $16.65 \mathrm{eV}$, respectively. Thus, the substrate work function, given by $\Phi_{\mathrm{s}}=\mathrm{h} \nu$ - $\mathrm{E}_{\text {cutoff }}$, shifts by $0.44 \mathrm{eV}$ after cycling and photoelectrochemical deposition of Rh. Because the In $4 \mathrm{~d}_{5 / 2}$ signal of InP at the valence band spectra does not change with conditioning steps, the shift of the secondary electron

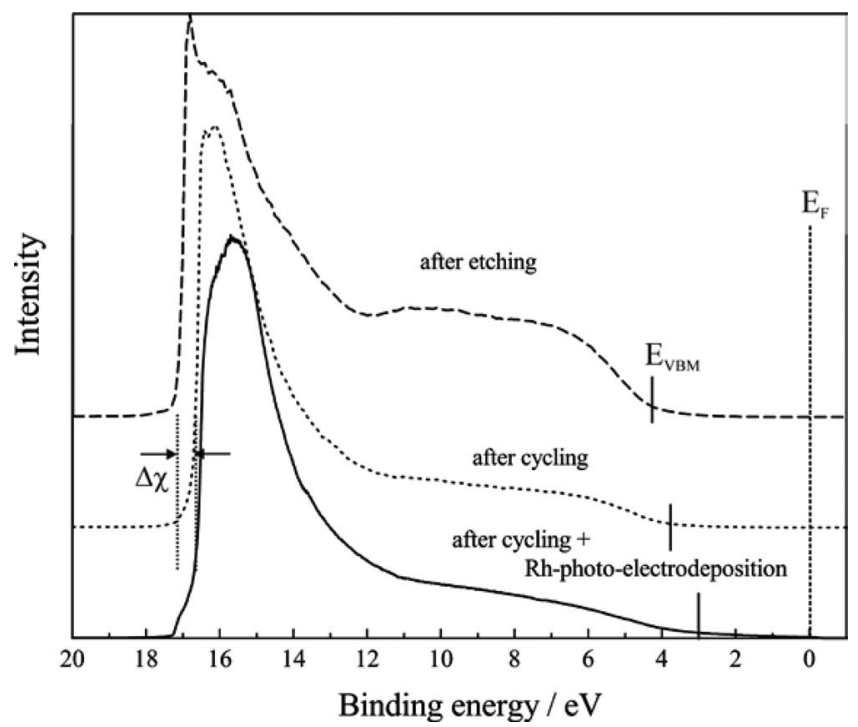

Figure 8. UPS-spectra obtained after each conditioning step, He I h $\nu=21.2$ eV. edge is not a consequence of surface band bending but arises from an increase of the electron affinity of the semiconductor.

The SRPES spectrum, taken after the photoelectrochemical cycling in $\mathrm{HCl}$ solution and photo electrodeposition of $\mathrm{Rh}$, shows an emission line at $198.2 \mathrm{eV}$, which can be assigned to the $\mathrm{Cl} 2 \mathrm{p}$ signal of $\mathrm{InCl}^{43}$ (see Fig. 9). The fact that the shift of the secondary electron edge appears after the surface treatment in the $\mathrm{HCl}$ solution leads to the assumption that the interfacial dipole is induced by formation of $\mathrm{In}-\mathrm{Cl}$ bonds. According to the Helmholtz-Perrin equation, ${ }^{44}$ the change of electron affinity is given by:

$$
\Delta \chi=\left(4 \pi \mathrm{e} / \varepsilon_{\mathrm{i}} \varepsilon_{0}\right) \mathrm{N} \mu(\theta)
$$

where $N$ ist the surface concentration of dipoles, $\varepsilon_{\mathrm{i}}$ is the dielectric constant of the dipole layer and $\mu(\theta)$ is the dipole moment of each polar bond as a function of the coverage fraction $\theta$. Assuming $\varepsilon_{i}=1$ and $\mu=3.79 \mathrm{D}$ for the In-Cl bond a density of $2.4 \times 10^{12}$ dipoles $\mathrm{cm}^{-2}$ can be calculated for a change of affinity of $0.44 \mathrm{eV}$. This represents about $0.5 \%$ of the surface density of In atoms on $\operatorname{InP}(100)$. At the moment, it is difficult to ascertain if the origin of the $\mathrm{In}-\mathrm{Cl}$ bonds is due to the formation of $\mathrm{InCl}$, owing to the instability of this compound in acid aqueous solution. It is rather probably, that the formation of dipoles arises as a consequence of electrosorption of $\mathrm{Cl}^{-}$on the

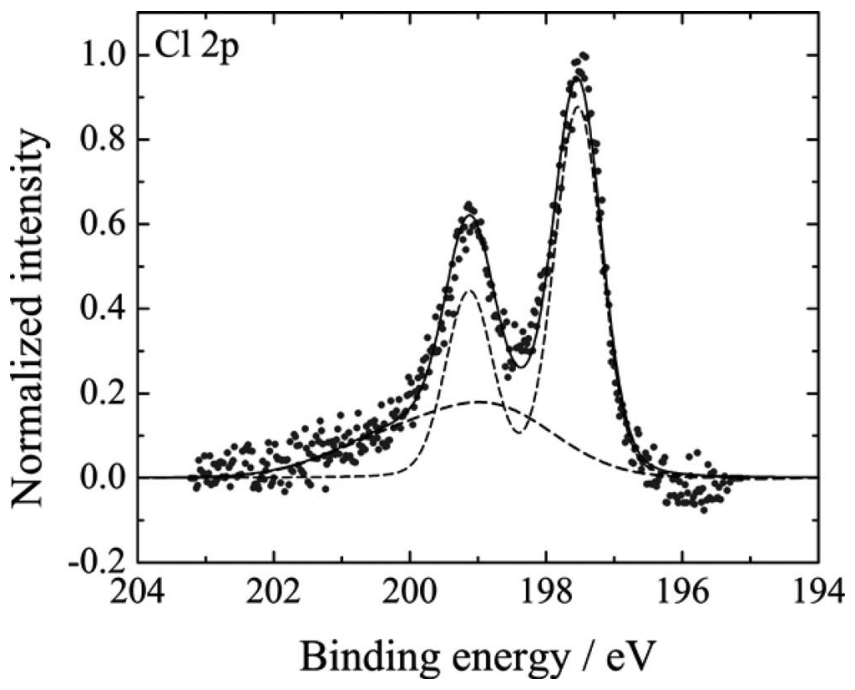

Figure 9. SRPES Cl 2p core level spectra of homoepitaxial InP (100) layers taken after the last conditioning step. $h \nu=300 \mathrm{eV}$. 


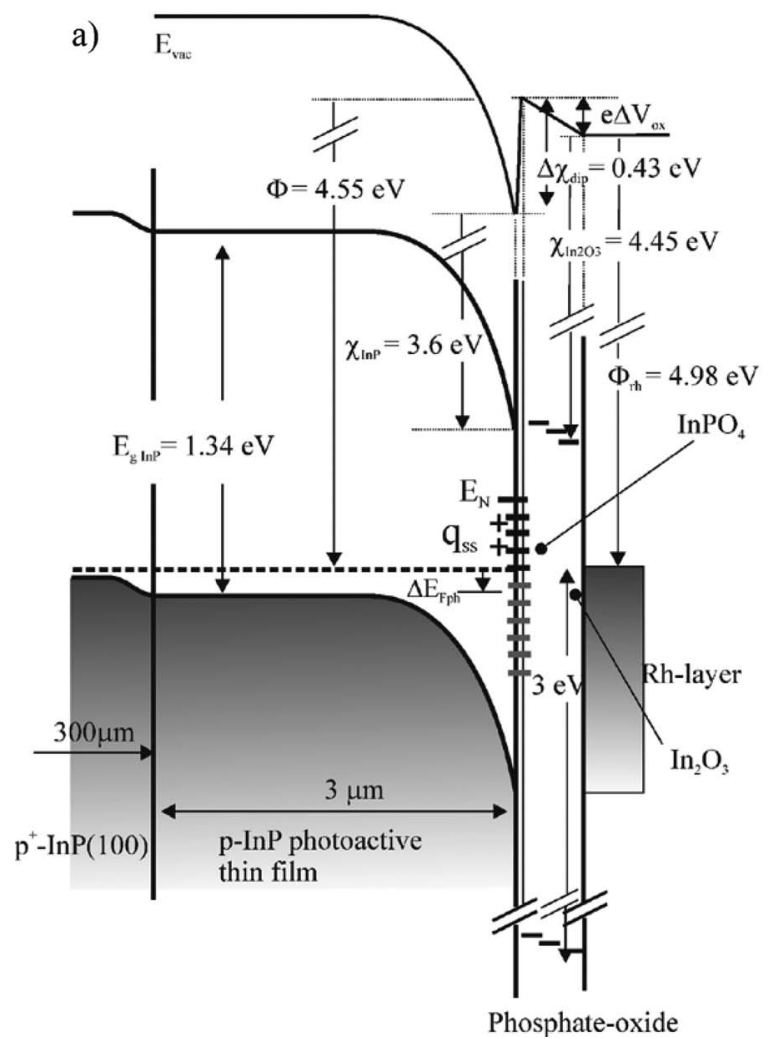

b)

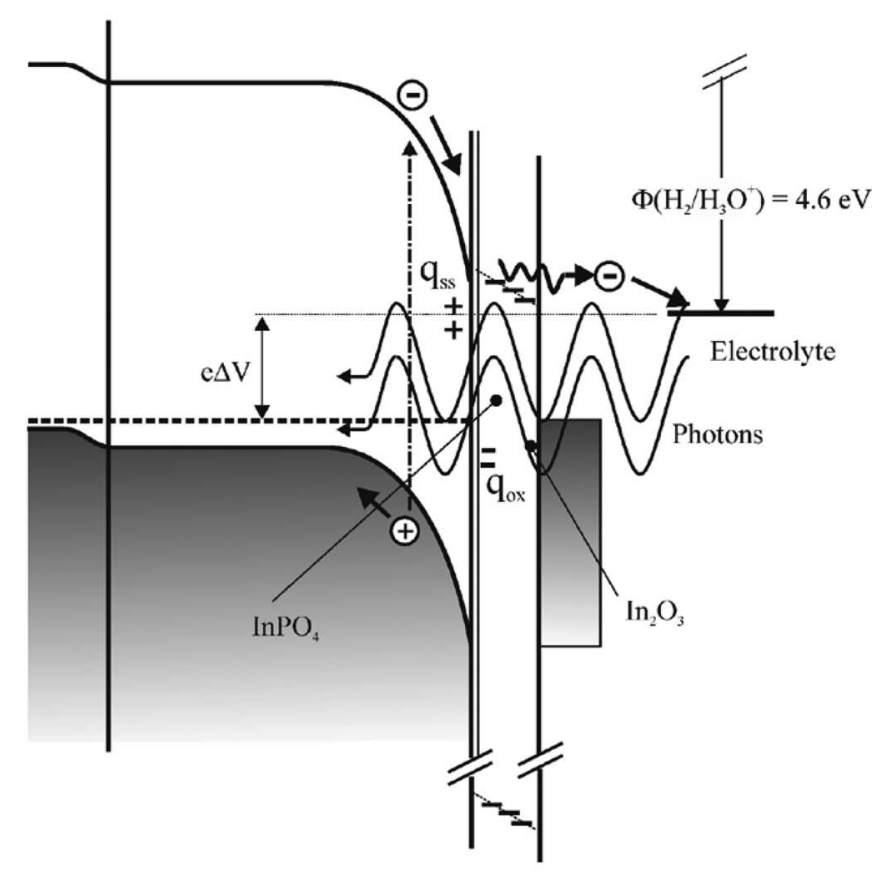

Figure 10. (a) Energy band diagram of the p-InP/phosphate-oxide/Rh interface; (b) Energy band diagram depicting the electron transfer processes at the $\mathrm{p}$-InP/phosphate-oxide/Rh photoelectrode in acid solution.

fresh surface of In metal clusters formed by photo-decomposition (reaction 1). Voltammetric experiments performed on In in aqueous and organic electrolytes have shown that $\mathrm{Cl}^{-}$adsorption takes place at $V>-1.1 \mathrm{~V}$ (SCE), i.e. $0.5 \mathrm{~V}$ more negative than the thermodynamic potential for the formation of $\mathrm{InCl}_{3} .{ }^{45}$ The electrosorption threshold is related to the very negative zero charge potential of this metal: $V_{\mathrm{pzc}}$ (In) $=-0.89 \mathrm{~V}$ (SCE). Recent SRPES valence band spectra taken after the electrodeposition of In from different salts have also shown a shift of the secondary electron edge after In deposition from $\mathrm{Cl}^{-}$containing electrolytes. ${ }^{46}$

Fig. 10a shows an energy band diagram constructed according to our investigations and reported data. An electron affinity of $3.6 \mathrm{eV}$ for the surface after etching was assumed. This value was reported by Lewerenz and Schulte for InP(100) before the electrochemical cycling conditioning step. ${ }^{47}$ This value results much lower than that reported for bulk InP of $4.4 \mathrm{eV}$. As reported for InP-Au Schottky contacts, ${ }^{48}$ the value of the electron affinity may vary spatially at the semiconductor surface due to some structural disorder such as nonstoichiometric and random distribution of $\mathrm{In}$ and $\mathrm{P}$ atoms. The affinity of the conditioned surface increases by $\Delta \chi=0.44 \mathrm{eV}$ due to the formation of $\mathrm{In}-\mathrm{Cl}$ dipoles. $\mathrm{In}_{2} \mathrm{O}_{3}$-like structures predominating at the outer part of the film introduce energy levels close to the conduction band edge of the oxide, near the conduction band edge of the substrate. Thus, lightinduced electron-hole pairs are separated by the electric field given by the semiconductor band bending and accelerated toward the catalytic $\mathrm{Rh}$ particles by resonance tunneling through the oxide film by the conduction band levels (see Fig. 10b). This process is enabled by the affinity increase introduced by the electrochemical cycling. Surface charges arise at the semiconductor surface for a Fermi level below the neutrality level $\mathrm{E}_{\mathrm{N}}$. These charges are compensated by the dielectric oxide. Thus, as depicted in Fig. 10b, part of the applied potential $\Delta \mathrm{V}$ at the photoelectrode is absorbed by the dielectric part of the oxide in detriment of the measured power characteristic (see Figure 3).
Optical properties. - The reflectance of bulk InP (solid curve) is contrasted in Fig. 11 with that of the photoelectrochemical produced $\mathrm{Rh} /$ phosphate-oxide/InP thin structure (dotted curve). A considerably lower reflectance of the device by about $30 \%$ indicates effective forward scattering into the absorber. A magnification of the reflectance increase below $2.5 \mathrm{eV}$ is shown as an inset, indicating signal variations resembling interference patterns. The simulated reflectance spectrum in the lower part of the figure (dashed curve) shows that the observed beneficial absorbance behavior of the device originates from the attenuated reflectance of the multi-layer composite structure. A simulation of the reflectance behavior at nearnormal incidence was made by applying the Maxwell-Garnett effective medium theory, according to which the dielectric functions of the respective nanoparticulate and rough interfaces can be calculated by: ${ }^{49}$

$$
\left(\varepsilon_{\text {eff }}-\varepsilon_{\mathrm{m}}\right) /\left(\varepsilon_{\mathrm{eff}}+2 \varepsilon_{\mathrm{m}}\right)=(1-\nu)\left[\left(\varepsilon-\varepsilon_{\mathrm{m}}\right) /\left(\varepsilon+2 \varepsilon_{\mathrm{m}}\right)\right]
$$

Here, $\varepsilon_{\text {eff }}$ refers to the effective dielectric constant of the mixed phase comprising a volumen fraction of material (v) with dielectric constant $\varepsilon$ (the host material) and (1-v)-fraction of material characterized by the dielectric function $\varepsilon_{\mathrm{m}}$ (the inclusions). According to the crosssectional TEM analysis in Figure 4a, a multi-layer system was assumed comprising a (graded) nanoparticulate $\mathrm{Rh}$ film, an $\mathrm{In}_{2} \mathrm{O}_{3}$ layer and bulk InP. Contributions of $\mathrm{InPO}_{4}$ and $\mathrm{In}\left(\mathrm{PO}_{3}\right)_{3}$ were not taken into account. Additionally, two interlayers were used at the $\mathrm{Rh} / \mathrm{In}_{2} \mathrm{O}_{3}$ and $\mathrm{In}_{2} \mathrm{O}_{3} / \mathrm{InP}$ boundaries in order to model a gradual transition between the respective films and to account for interfacial roughness. For the nanoparticulate Rh film, bulk dielectric data were used. ${ }^{50}$ The limited electron mean free path in nanosized metal objects, resulting in modified dielectric data in dependence on particle diameter, was not considered here due to the statistical size distribution of the Rh particles. Optical properties of $\operatorname{In}_{2} \mathrm{O}_{3}$ were taken from Ref. 51. The dielectric function of InP was used according to measurements by spectroscopic ellipsometry. ${ }^{52}$ Initial values of film thickness and 

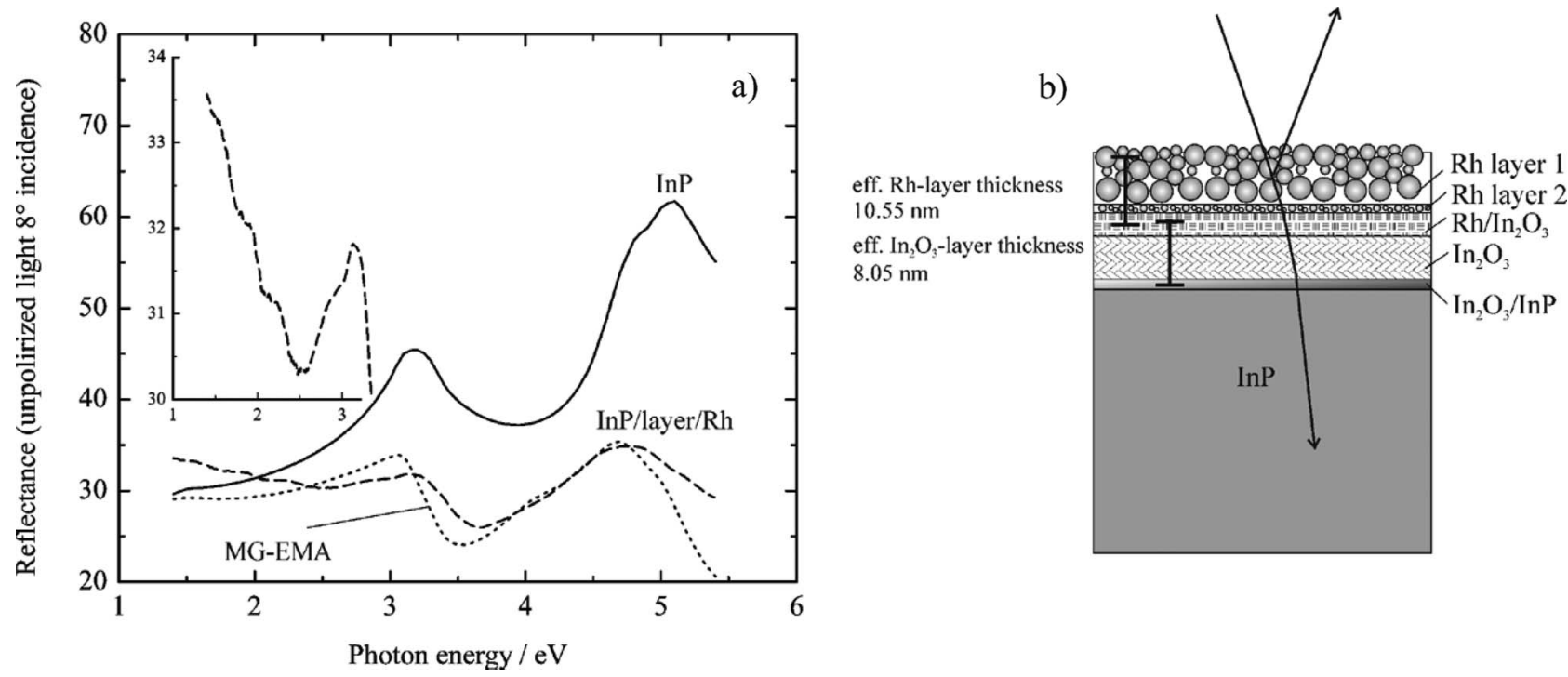

Figure 11. (a) Reflectance of $\operatorname{InP}$ (solid line) and the $\mathrm{Rh} / \mathrm{In}_{\mathrm{x}} \mathrm{O}_{\mathrm{y}} / \mathrm{InP}$ photoelectrode (dotted line). The inset shows a magnification of interference patterns below $2.5 \mathrm{eV}$; (dotte line) simulated reflectance behavior according to Maxwell-Garnett effective medium theory; (b) Scheme depicting the modeling of the photoelectrode structure.

material composition, deduced from TEM and AFM investigations, were adapted in subsequent numerical calculations to obtain an approximate simulation of the measured reflectance. Values for the respective film thicknesses and volume fractions were chosen according to: Rh-air (7.9 nm, 40\%/60\%), Rh-air $(0.5 \mathrm{~nm}, 74 \% / 26 \%), \mathrm{Rh}-\mathrm{In}_{2} \mathrm{O}_{3}$ interface $(4.3 \mathrm{~nm}, 29 \% / 71 \%), \mathrm{In}_{2} \mathrm{O}_{3}(4.6 \mathrm{~nm}, 100 \%), \mathrm{In}_{2} \mathrm{O}_{3}$ - InP interface $(2.4 \mathrm{~nm}, 96 \% / 4 \%)$. Therefore, the overall layer thickness of the nanoparticulate Rh-film amounts to $10.55 \mathrm{~nm}$ while the actual $\mathrm{In}_{2} \mathrm{O}_{3}$ layer thickness in Figure $4 \mathrm{a}$ is $8.05 \mathrm{~nm}$. Differences to TEM analysis result from fully accounting for surface and interfacial roughness. Formulae for the determination of the reflectance of multi-layer systems are given in the appendix. The difference between simulated and measured reflectance values, still amounting to $\pm 8 \%$, points to several effects not considered in the simulation: firstly, the actual optical constants of the $\mathrm{In}_{2} \mathrm{O}_{3}$ interlayer, modified electrochemically, are presently unknown and may deviate from the values assumed here; secondly, the close mutual distance of the Rh particles, at or beyond the percolation threshold, may result in complex effects not described by effective medium theory. The increase of the reflectance below $2.5 \mathrm{eV}$, for instance, could indicate commencing metallic reflection by the almost closed Rh film which is, for higher photon energies, nearly transparent. ${ }^{53}$

\section{Conclusions}

A homoepitaxial thin-film $\mathrm{p}-\mathrm{InP} / \mathrm{phosphate-oxide/Rh} \mathrm{hetrostruc-}$ ture was presented with $14.5 \%$ record efficiency in light-induced hydrogen evolution. Based on careful structural, chemical, electronic and optical analysis, the advantageous device architecture could be analyzed in detail. Local $\mathrm{In}_{2} \mathrm{O}_{3}$-like structural regions introduce energy levels near the semiconductor conduction band edge which impart conductivity to the $7 \mathrm{~nm}$ thick dielectric phosphate-oxide film. Interfacial dipole attributed to chloride adsorption on segregated In was deduced from ultraviolet spectroscopy. These results account for the observed highly efficient performance in hydrogen evolution but also point to further possible enhancements in both electron-transfer across the oxide layer and enhancement in light absorption. While the former depends on optimization of the oxide quality, the latter refers to advanced light-incoupling strategies extensively discussed for photovoltaic devices.

\section{Acknowledgments}

The authors acknowledge the support given by the Collaborating Research Group (CRG), which maintains the SoLiAS system at Bessy II. Financial support was given by the BMBF federal project No. 03 SF 0353A-E which is greatly acknowledged.

\section{Appendix}

Figure A1 represents the multilayer structure consisting of a stack of layers with thickness $d_{i}$ and dielectric constants $\varepsilon_{i}$. The system is regarded as an optical system with one input and one output port. At each interface, the incident and reflected waves at the

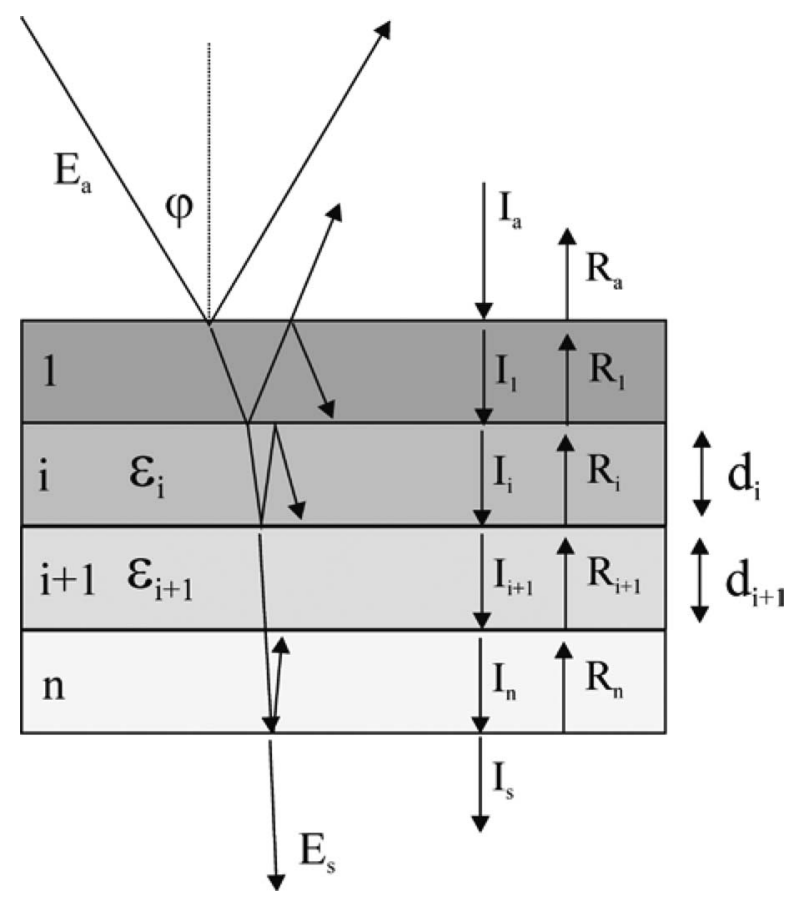

Figure A1. Scheme showing the trajectory of incident light on at layered structure. 
interface between $i$ and $i+1$ in the layer $i$ are related to the incident and reflected waves in the layer $\mathrm{i}+1$ by:

$$
\left[\begin{array}{c}
I_{i+1} \\
R_{i}
\end{array}\right]=\left[\begin{array}{cc}
t_{i, i+1} & r_{i+1, i} \\
r_{i, i+1} & t_{i+1, i}
\end{array}\right]\left[\begin{array}{c}
I_{i} \\
R_{i+1}
\end{array}\right]=M_{i}\left[\begin{array}{c}
I_{i} \\
R_{i+1}
\end{array}\right]
$$

where $I_{i}$ and $R_{i}$ are the amplitudes of the incident and reflected waves in the layer $i$ and $t_{i j}$ and $r_{i j}$ are the complex transmission and reflection coefficients of the transfer matrix $M_{i}$. For the complete layered system, the incident and reflected amplitudes are related by the total matrix $\mathrm{M}_{\mathrm{T}}$ as: ${ }^{54}$

$$
\left[\begin{array}{c}
I_{a} \\
R_{a}
\end{array}\right]=M_{T}\left[\begin{array}{c}
I_{s} \\
R_{s}
\end{array}\right]
$$

with:

$$
\begin{aligned}
M_{T}= & {\left[\begin{array}{ll}
m_{11} & m_{12} \\
m_{21} & m_{22}
\end{array}\right]=\left[\begin{array}{cc}
1 & r_{a 1} \\
r_{a 1} & 1
\end{array}\right]\left[\begin{array}{cc}
1 & r_{12} \\
r_{12} e^{-2 i \Phi_{1}} & e^{-2 i \Phi_{1}}
\end{array}\right]\left[\begin{array}{cc}
1 & r_{23} \\
r_{23} e^{-2 i \Phi_{2}} & e^{-2 i \Phi_{2}}
\end{array}\right] \times \ldots } \\
& \times\left[\begin{array}{cc}
1 & r_{(n-1) n} \\
r_{(n-1) n} e^{-2 i \Phi_{n}} & e^{-2 i \Phi_{n}}
\end{array}\right]
\end{aligned}
$$

$\mathrm{r}_{\mathrm{i}(\mathrm{i}+1)}$ in Eq. A3 denotes the reflection coefficient at the boundary between the $\mathrm{i}^{\text {th }}$ and the $(i+1)^{\text {th }}$ layer. For p-polarized light, for instance, $r_{i(i+1)}$ is given by:

$$
r_{i(i+1) p}=\frac{\varepsilon_{i+1} \sqrt{\varepsilon_{i}-\varepsilon_{a} \sin ^{2} \varphi}-\varepsilon_{i} \sqrt{\varepsilon_{i+1}-\varepsilon_{a} \sin ^{2} \varphi}}{\varepsilon_{i+1} \sqrt{\varepsilon_{i}-\varepsilon_{a} \sin ^{2} \varphi}+\varepsilon_{i} \sqrt{\varepsilon_{i+1}-\varepsilon_{a} \sin ^{2} \varphi}}
$$

For near-normal incidence $\left(\varphi \sim 0^{\circ}\right)$ Eq. A4 becomes independent on the polarization state and reduces to:

$$
r_{i(i+1) p}=\frac{\varepsilon_{i+1} \sqrt{\varepsilon_{i}}-\varepsilon_{i} \sqrt{\varepsilon_{i+1}}}{\varepsilon_{i+1} \sqrt{\varepsilon_{i}}+\varepsilon_{i} \sqrt{\varepsilon_{i+1}}}
$$

The exponent $\Phi_{i}=\frac{2 \pi d_{i}}{\lambda} \sqrt{\varepsilon_{i+1}-\varepsilon_{i} \sin ^{2} \varphi}$ in Eq. A3 accounts for the phase shift at the respective boundary and depends upon the dielectric functions $\varepsilon_{i}, \varepsilon_{i+1}$ and the layer thickness $\mathrm{d}_{\mathrm{i}}$ of the $\mathrm{i}^{\text {th }}$ layer. The complex reflection coefficient of the multi-layer structure for $\mathrm{p}$ - or s-polarized light, $\mathrm{r}_{\mathrm{p}}$ and $\mathrm{r}_{\mathrm{s}}$, respectively, is given by:

$$
r_{p / s}=\frac{m_{21}}{m_{11}}
$$

The resulting reflectance for light, incident at an angle $\varphi$, is then given by the absolute value: $R_{p / s}=r_{p / s} \cdot r_{p / s}^{*}$ where $r_{p / s}^{*}$ is the complex conjugate of the reflection coefficient $r_{p / s}$.

As indicated in the text, the dielectric properties of interfacial regions were modeled by Maxwell-Garnett effective medium approximation according to:

$$
\frac{\varepsilon_{e f f}-\varepsilon_{m}}{\varepsilon_{e f f}+2 \varepsilon_{m}}=(1-\nu) \frac{\varepsilon-\varepsilon_{m}}{\varepsilon+2 \varepsilon_{m}}
$$

where $\varepsilon_{\text {eff }}$ refers to the resulting effective dielectric constant of the mixed phase comprising a v-fraction of material with dielectric constant $\varepsilon$ (the host material) and (1-v)-fraction of material characterized by the dielectric function $\varepsilon_{M}$ (the inclusions). Particularly for the $\mathrm{Rh}$ film, a mixed phase of $\mathrm{Rh}$ and air was assumed with increasing $\mathrm{Rh}$ content toward the $\mathrm{In}_{2} \mathrm{O}_{3} / \mathrm{InP}$ interface.

Application of the above formulas to a seven layer system (including the ambient, see Fig. 11b) resulted in an approximate simulation of the observed reflectance behavior of the $\mathrm{Rh} /$ phosphate-oxide/InP device.

\section{References}

1. A. J. Bard and M. A. Fox, Acc. Chem. Res., 28, 141 (1995).

2. F. Barbir, Solar Energy, 78, 661 (2005).

3. N. S. Lewis, Nature, 414, 589 (2001).

4. A. J. Nozik, Appl. Phys. Lett., 29, 150 (1976).

5. W. Lubitz, E. J. Reijerse, and J. Messinger, Energy Environ. Sci., 1, 15 (2008).

6. C. A. Grimes, O. K. Varghese, and S. Ranjan, in Light, Water, Hydrogen, Springer Verlag, New York, 2008.

7. Th. Meyer, J. Acc. Chem. Res., 22, 163 (1989).
8. M. Woodhouse, G. S. Herman, and B. A. Parkinson, Chem Mater, 17, 4318 (2005).

9. J. W. Schultze and M. M. Lohrengel, Electrochim. Acta, 45, 2499 (2000).

10. M. A. Fox and M. T. Dulay, Chem. Rev., 93, 341 (1993).

11. A. Fujishima and K. Honda, Nature, 238, 37 (1972).

12. O. Khaselev and J. A. Turner, Science, 280, 425 (1998).

13. A. B. Brown and M. A. Green, Phys. E, 14, 96 (2002).

14. G. Peharz, F. Dimrotha, and U. Wittstadta, Int. J. Hydrogen Energy, 32, 3248 (2007).

15. J. R. Bolton, S. J. Strickler, and J. S. Connolly, Nature, 316, 495 (1985).

16. S. W. Boettcher, E. L. Warren, M. C. Putnam, E. A. Santori, D. Turner-Evans, M. D. Kelzenberg, M. G. Walter, J. R. McKone, B. S. Brunschwig, H. A. Atwater, and N. S. Lewis, J. Am. Chem. Soc., 133, 1216 (2011).

17. A. Heller and R. G. Vadimsky, Phys. Rev. Lett., 46, 1153 (1981).

18. J. J. Schermer, G. J. Bauhuis, P. Mulder, E. J. Haver-kamp, J. van Deelen, A. T. J. van Niftrik, and P. K. Larsen, Thin Solid Films, 511-512, 645 (2006).

19. A. Polman and H. A. Atwater, Nature Materials, 11, 174 (2012).

20. S. Pillai, K. R. Catchpole, T. Trupke, and M. A. Green, J. Appl. Phys., 101, 093105 (2007).

21. H. A. Atwater and A. Polman, Nature Materials, 9, 205 (2010).

22. T. Hannappel, L. Töben, K. Möller, and F. J. Willig, Electron. Mat., 30, 1425 (2001).

23. T. Hannappel, S. Visbeck, K. Knorr, J. Mahrt, M. Zorn, and F. Willig, Appl. Phys. A, 69, 427 (1999).

24. P. Vogt, A. M. Frisch, T. Hannappel, S. Visbeck, F. Willig, C. Jung, N. Esser, W. Braun, and W. Richter, Phys. Stat. Sol. B, 215, 737 (1999).

25. H. J. Lewerenz, Chem. Soc. Rev., 26, 239 (1997).

26. S.-H. Lo, D. A. Buchanan, Y. Taur, and W. Wang, IEEE Electron. Dev. Lett., 18, 209 (1997).

27. NIST, XPS Database, Web. Edn., National Insitute of Standards and Technology, Gaitherburg, MD, 2004.

28. G. Hollinger, E. Bergignat, J. Joseph, and Y. Robach, J. Vac. Sci. Technol. A, 3, 2082 (1985).

29. G. Chen, S. B. Visbeck, D. C. Law, and R. F. Hicksa, J. Appl. Phys., 91, 9362 (2002).

30. CRC Handbook of Chemistry and Physics 1999-2000: A Ready-Reference Book of Chemical and Physical Data, $81^{\text {st }}$ ed., D. R. Lide (Ed.), CRC Press, Boca Raton, FL, 2000.

31. Y. Robach, J. Joseph, E. Bergignat, and G. Hollinger, J. Electrochem. Soc., 136, 2957 (1989).

32. G. Hollinger, J. Joseph, Y. Robach, E. Bergignat, B. Commere, P. Viktorovitch, and M. Froment, J. Vac. Sci. Technol. B, 5, 1108 (1987).

33. M. Faur, M. Faur, D. T. Jayne, M. Goradia, and C. Goradia, Surf. Interface Anal., 15, 641 (1990).

34. Y. Sun, Z. Liu, F. Machuca, P. Pianetta, and W. E. Spicer, J. Vac. Sci. Technol. A, 21, 219 (2003).

35. A. Klein, Appl. Phys. Lett., 77, 2009 (2000).

36. P. E. Chye, C. Y. Su, I. Lindau, C. M. Graner, P. Pianetta, and W. E. Spicer, Surf. Sci., 88, 439 (1979).

37. N. V. Smith, G. K. Wertheim, S. Hüfner, and M. M. Traum, Phys. Rev. B, 10, 3197 (1974).

38. J. M. Moison, M. Van Rompay, and M. Bensoussan, Appl. Phys. Lett., 48, 1362 (1986).

39. M. Miczek, B. Adamovicz, and H. Hasegawa, Surf. Sci., 507-510, 240 (2002).

40. K. Horn, M. Alonso, and R. Cimino, Appl. Surf. Sci., 56-58, 271 (1992).

41. R. L. Weiher and R. P. Ley, J. Appl. Phys., 37, 299 (1966).

42. O. Lang, C. Pettenkofer, J. F. Sánchez-Royo, A. Segura, A. Klein, and W. Jaegermann, J. Appl. Phys., 86, 5687 (1999).

43. B. H. Freeland, J. J. Habeeb, and D. G. Tuck, Can. J. Chem., 55, 1527 (1977).

44. C. T. Campbell, Annu. Rev. Phys. Chem., 41, 775 (1990).

45. A. G. Muñoz and J. B. Bessone, Electrochim. Acta, 43, 1067 (1998).

46. A. G. Muñoz, W. Calvet, W. Jaegermann, and H. J. Lewerenz, to be published.

47. K. H. Schulte and H. J. Lewerenz, Electrochim. Acta, 47, 2633 (2002).

48. K. Hattori and Y. Izumi, J. Appl. Phys., 52, 5699 (1981).

49. J. C. Maxwell-Garnett, Philos. Trans. R. Soc. London, 203, 385 (1904).

50. E. D. Palik (Ed.), Handbook of Optical Constants of Solids, Academic Press New York 1991

51. P. Prathap, Y. P. V. Subbaiah, M. Devika, and K. T. Rama-Krishna Reddy, Mater. Chem. Phys., 100, 375 (2006).

52. D. E. Aspnes and A. A. Studna, Phys. Rev. B, 27, 985 (1983)

53. A. Heller, D. E. Aspnes, J. D. Porter, T. T. Sheng, and R. G. Vadimsky, J. Phys. Chem., 89, 4444 (1985).

54. P. Yeh, in Optical Waves in Layered Media, John Wiley \& Sons, US, 1988. 